\title{
Vesicular stomatitis New Jersey virus (VSNJV) infects keratinocytes and is restricted to lesion sites and local lymph nodes in the bovine, a natural host
}

\author{
Charles F.C. SCHERER ${ }^{\mathrm{a}, \mathrm{b}, \mathrm{c}}$, Vivian O’DONNELL ${ }^{\mathrm{a}, \mathrm{d}}$, William T. GOLDE ${ }^{\mathrm{a}}$, \\ Douglas GREGG ${ }^{\text {a }}$, D. Mark ESTES ${ }^{\text {b,c }}$, Luis L. RoDRIGUEZ ${ }^{\text {a* }}$ \\ ${ }^{a}$ Plum Island Animal Disease Center, Agricultural Research Service, United States Department of \\ Agriculture, PO Box 848, Greenport, NY 11944, USA \\ ${ }^{\mathrm{b}}$ University of Missouri, College of Veterinary Medicine, Department of Veterinary Pathobiology, \\ Columbia, MO 65251, USA \\ ${ }^{c}$ Department of Microbiology and Immunology, University of Texas Medical Branch, \\ Galveston, TX 77555, USA \\ ${ }^{\mathrm{d}}$ Department of Pathobiology, University of Connecticut, Storrs CT 06269, USA
}

(Received 16 August 2006; accepted 19 October 2006)

\begin{abstract}
Inoculation of vesicular stomatitis New Jersey virus (VSNJV) by skin scarification of the coronary-band in cattle, a natural host of VSNJV, resulted in vesicular lesions and $6-8 \log _{10}$ $\mathrm{TCID}_{50}$ increase in skin virus titers over a $72 \mathrm{~h}$ period. Virus infection was restricted to the lesion sites and lymph nodes draining those areas but no virus or viral RNA was found in the blood or in 20 other organs and tissues sampled at necropsy. Scarification of flank skin did not result in lesions or a significant increase in viral titer indicating that viral clinical infection is restricted to skin inoculation at sites where lesions naturally occur. Viral antigens co-localized primarily with keratinocytes in the coronary band, suggesting these cells are the primary site of viral replication. Viral antigen also co-localized with few MHC-II positive cells, but no co-localization was observed in cells positive for macrophage markers. Although granulocyte infiltration was observed in lesions, little viral antigen co-localized with these cells. This is the first detailed description of VSNJV tissue distribution and infected cell characterization in a natural host. The pathogenesis model shown herein could be useful for in-vivo tracking of virus infection and local immune responses.
\end{abstract}

vesicular stomatitis / bovine / pathogenesis / confocal microscopy / keratinocytes

\section{INTRODUCTION}

Vesicular stomatitis virus (VSV) is widely used as a laboratory research tool for RNA virus evolution and to evaluate immune function. More recently it has had

* Corresponding author:

luis.rodriguez@ars.usda.gov application as a vector for experimental vaccine delivery and for anti-tumor therapy $[1,18]$. In the nature VSV is an important livestock pathogen causing vesicular stomatitis (VS) a disease characterized by the appearance of vesicular lesions in the mouth, feet and udders, of cattle, pigs and horses. In cattle and swine these lesions are clinically undistinguishable 
from foot-and-mouth disease, a devastating disease of livestock [20]. VSV has been shown to be transmitted by insect bites $[6,14,27]$ but transmission by direct contact between animals has also been demonstrated [15, 23]. The mechanisms of disease remain unclear, although field observations indicate that many infections do not result in overt clinical disease and many susceptible species living in endemic areas possess neutralizing antibody titers to VSV [16, 19].

Most knowledge pertaining to VSV pathogenesis is derived from studies involving laboratory rodents where clinical signs are not vesicular in nature, but rather the infection manifests as encephalitis and death depending on host factors such as age, route of inoculation and viral strain $[7,9]$. Neurological symptoms have not been reported in natural VSV hosts (cattle, swine, horses) [20]. The basic mechanisms of VSV infection remain unclear, but experiments in swine suggest that the inoculation site determines clinical outcome. Vesicular lesions are observed only when the virus is intradermally inoculated at specific sites where lesions are observed during natural infections (snout, lip, feet) and instead subclinical infection occurs when virus is inoculated intradermally at other sites (i.e. ear, abdomen) or by the intranasal or intravenous routes $[11,15]$. Recently, it was further shown that vesicular lesions only developed when experimentally infected black flies (Simulium vittatum) were allowed to feed on the snout but not when flies fed on the abdomen of swine [14].

Little is known about the basic cellular and molecular mechanisms mediating VSV pathogenesis in its natural hosts. Information regarding the primary sites of virus replication and the cell types involved in supporting viral growth and those involved in controlling the infection remain scarce. Previous studies on VSV inoculation in natural hosts have been limited to the description of gross pathology and histopathology of the lesions without specific identification of cell types involved in early viral infection.

This study describes early events of vesicular stomatitis New Jersey virus (VSNJV) infection in cattle utilizing a novel coronary band scarification inoculation model combined with analyses by immunohistochemistry, confocal microscopy and real-time RT-PCR. The tissue distribution of virus and the identity of the cell types infected during early phases of disease are described.

\section{MATERIALS AND METHODS}

\subsection{Animals and virus}

Adult (18 to 24 months) Holstein steers weighing 500-700 lb were obtained from an experimental-livestock provider (Thomas-Morris Inc., PA, USA) and kept in the biosafety level 3 facility at Plum Island Animal Disease Center for at least one week prior to initiation of the experiments. All animal inoculations were performed with a VSNJV field strain obtained from tongue epithelium of a bovine naturally infected during the 1995 epidemic in Colorado (95COB). This virus was identified as VSNJV by virus neutralization and sequencing of the complete viral genome [21]. The virus was propagated by passing once in baby hamster kidney cells (BHK-21) infected at 0.01 multiplicity of infection. Viral stock was titrated in BHK21 cells, and kept in aliquots at $-70{ }^{\circ} \mathrm{C}$.

\subsection{Inoculation procedure}

Animals were sedated with xylazine and the coronary band areas were shaved, prior to the epidermis being pricked 20 times using a dual tip skin test applicator (DuotipTest, Lincoln Diagnostics, Decatur, IL, 
USA). Virus inoculum was placed on the scarified area in $100 \mu \mathrm{L}$ of Dulbecco Modified Eagle Medium containing 2\% fetal bovine serum (FBS) (DMEM2). The area under the inoculum was then scarified 20 additional times with the animals restrained in a stationary position for 1-2 min until the inoculum was adsorbed. A total of thirteen animals were used in this study. Six animals, housed in three separate rooms, received $10^{7} \mathrm{TCID}_{50} /$ foot $_{\text {in }}$ each of all four feet; one animal (\#102) was inoculated only on the right feet and mockinoculated on the left feet. Animals 12 and 148 were inoculated with $10^{7}$ TCID $_{50}$ of VSNJV by intradermal injection or scarification on the skin of the flank and kept in separate rooms. One animal (\#699) was inoculated by injection of $10^{7.0}$ TCID $_{50}$ distributed in four sites on the dorsal epithelium of the tongue and house alone. All inoculations were performed with the same viral stock.

Three non-inoculated animals kept in separate rooms were used as negative controls and sampled similarly. Clinical signs, temperature, appetite, and attitude were evaluated daily for all animals. Clinical disease was scored by determining the size and number of lesions, a value of 1 was given to small lesions and a value of 2 for large lesions on each foot or on the tongue (a maximum score of 10 would indicate large vesicles in all feet and on the tongue).

\subsection{Sampling}

Punch biopsies were obtained from sedated animals using disposable $6 \mathrm{~mm}$ skin biopsy punch (Miltex, Inc., Bethpage, NY, USA) before inoculation, and at 6, 12, 24, 48 and 72 hours post-inoculation (hpi). Two biopsies were taken at each time point from different feet; one was fixed in $10 \%$ buffered formalin for $24 \mathrm{~h}$ before processing for histological examinations and the other one was snap-frozen in liquid ni- trogen for RNA extraction, virus isolation and confocal microscopy. Oropharyngeal fluid (OPF), plasma and blood samples were also obtained and kept at $-70{ }^{\circ} \mathrm{C}$ until being processed. In four of the animals inoculated in the coronary band, biopsies were also taken $20 \mathrm{~min}$ after inoculation.

Eight animals were euthanized at $72 \mathrm{hpi}$ and the following tissues were collected for RT-PCR and virus isolation: prescapular, popliteal, axillary, mediastinal, mesenteric, iliac, prefemoral, retropharyngeal, parotid, and submandibular lymph nodes; coronary band, tongue, tonsils, lung, heart, liver, spleen, kidney, small intestine (duodenum), large intestine (cecum), snout skin, mandibular salivary glands, nasal epithelium and brain (olfactory area). Animals 12 and 148, inoculated on the flank, were euthanized at $48 \mathrm{hpi}$ and only skin samples and major lymph nodes were collected.

\subsection{Virus isolation}

Tissues were macerated using a mortar and pestle in $2 \mathrm{~mL}$ of Minimal Essential Medium containing $400 \mathrm{U} / \mathrm{mL}$ of penicillin, $400 \mathrm{U} / \mathrm{mL}$ of streptomycin, and $10 \mu \mathrm{g} / \mathrm{mL}$ of amphotericin B (MEM). Macerated samples were centrifuged for $5 \mathrm{~min}$ and dilutions of the clarified supernatants were inoculated onto monolayers of BHK21 cells as previously described [8]. Blood, plasma and OPF samples were tested similarly by direct inoculation of cell monolayers with serial sample dilutions. Monolayers were rinsed with MEM 2 hpi and replaced with fresh medium. Cultures were observed for cytopathic effect (CPE) at 24, 48 and 72 hpi. After $72 \mathrm{~h}$ supernatant from each CPE-positive well was saved and the presence of VSNJV antigens was confirmed by direct staining of the fixed cells using biotinylated VSNJV-specific antibodies as previously described [12]. Flasks negative for CPE after $72 \mathrm{~h}$ were frozen, 
thawed and supernatants were reconfirmed negative by real-time RT-PCR.

\subsection{Immunohistochemistry}

Immunohistochemistry (IHC) was performed as previously described by Sur et al. [25]. Briefly, $3 \mu \mathrm{M}$ paraffin sections were placed on ProbeOn ${ }^{\mathrm{TM}}$ Plus slides (Fisher Scientific, Pittsburgh, PA, USA), deparaffinized in xylene and dehydrated in graded alcohol. Antigen retrieval was done in two ways, either using citrate solution (DAKO Cytomation, Denmark) for $5 \mathrm{~min}$ in an autoclave or 3 cycles of $3 \mathrm{~min}$ at medium power in a microwave using 0.1 M Tris-HCL pH 8.0-8.2 as described by Tanimoto and Ohtsuki [26]. Tissues were blocked with a $5 \%$ solution of normal rabbit serum in PBS containing $0.01 \%$ Tween 20 (PBST) for $10 \mathrm{~min}$ at room temperature, washed in PBST and incubated overnight at $4{ }^{\circ} \mathrm{C}$ with antiVSNJV guinea pig antibody (1:5000 dilution in PBST) in a humid chamber. After three washes with PBST, a secondary anti-guinea pig IgG conjugated with peroxidase (Vector Laboratories, Burlingame, CA, USA) was applied according to the manufacturer's instructions. After a final rinse with $0.1 \mathrm{M}$ Tris $\mathrm{pH}$ 8.0, substrate solution was applied (Vector Red kit, Vector Laboratories) following the manufacturer's protocol. After $20 \mathrm{~min}$, the slides were washed and counterstained with Gill Haematoxylin. Sections of VSNJVinfected tissue were used as positive controls and sections of mock inoculated tissues were used as the negative control.

\subsection{Confocal immunofluorescence microscopy}

For confocal microscopy, 3-5 $\mu \mathrm{m}$ thick sections of cryopreserved tissues were sectioned with a cryomicrotome and fixed with acetone for $10 \mathrm{~min}$ at $-20{ }^{\circ} \mathrm{C}$. After fixation, the sections were blocked for $1.5 \mathrm{~h}$ in PBS, $20 \%$ fetal bovine serum, 2\% BSA (blocking buffer) at $37^{\circ} \mathrm{C}$. Primary antibodies, anti-VSNJV (guinea pig polyclonal, 1/1000), anticytokeratin (a marker for keratinocytes, IgG2a, clone K8.13, Sigma, 1/100), antihuman HLA-DR (a marker for dendritic cells, B-cells, macrophages and monocytes, IgG1, clone 1B5, DAKO Cytomation, 1/500), or MAC-387 (a marker for granulocytes, monocytes and tissue macrophages, DAKO Cytomation, 1/200) were diluted in blocking buffer and incubated with the slides overnight at $4{ }^{\circ} \mathrm{C}$ in a humid chamber. When double labeling was performed, the slides were incubated with both antibodies together. After being washed five times with PBS, the slides were incubated with the appropriate secondary antibodies; goat anti-guinea pig (1/400, Alexa Fluor 594, Molecular Probes, Eugene OR, USA), or goat antimouse isotype specific (1/400, Alexa Fluor 488, Molecular Probes); and diluted in blocking buffer for $1.5 \mathrm{~h}$ at $37{ }^{\circ} \mathrm{C}$. Following this incubation, the slides were washed five times with PBS, counterstained with the nuclear staining TOPROiodide 642/661 (Molecular Probes) for 5 min at RT, mounted and examined using a Leica scanning confocal microscope. Data were collected using appropriate controls lacking the primary antibodies, as well as using uninfected sections to give the negative background levels. The captured images were adjusted for contrast and brightness using Adobe Photoshop software.

\subsection{RNA extraction and Quantitative Real Time PCR (Q-RT-PCR)}

Total RNA extraction from tissues, plasma, and OPF samples was done using TRIZOL reagent (Invitrogen Corporation, 
Carlibad, CA, USA) following the protocol supplied by the manufacturer. Total RNA from PBMC was extracted using the Qiagen RNEasy kit (Qiagen, Valencia, CA, USA), per manufacturer's protocol. RNA samples were kept at $-20{ }^{\circ} \mathrm{C}$ until analysis. Semi-quantitative real-time PCR specific for VSNJV was done using a nucleocapsid-specific test with the following primers: forward 5'GCACTTCCTGATGGGAAATCA3', reverse 5'GGGAAGCCATTTATCCTCA3' and FAM-labeled probe 5'ACCCTGACCGTTCTG3' (Applied Biosystems, Foster City, CA, USA). The RT-PCR reaction was done using the TaqMan ${ }^{\circledR}$ EZ RT PCR core reagent kit (Applied Biosystems), containing $300 \mathrm{nM}$ of each primer, $25 \mathrm{mM}$ Manganese acetate, $10 \mathrm{mM}$ dNTP with $20 \mathrm{mM}$ of dUTP, $2.5 \mathrm{U}$ of $r$ Tth polymerase, $0.25 \mathrm{U}$ of AmpErase $\mathrm{UNG}^{\circledR}, 2 \mu \mathrm{L}$ of template RNA and rnasefree water in a $25 \mu \mathrm{L}$ reaction volume. The cycling profile was as follows: $50{ }^{\circ} \mathrm{C}$ for $2 \mathrm{~min}, 58{ }^{\circ} \mathrm{C}$ for $30 \mathrm{~min}$ for reverse transcription, hold for $95{ }^{\circ} \mathrm{C}$ for $5 \mathrm{~min}$ to inactivate AmpErase and then 40 cycles of $95{ }^{\circ} \mathrm{C}$ for $20 \mathrm{~s}$ and $60{ }^{\circ} \mathrm{C}$ for $1 \mathrm{~min}$. The results were expressed as $\mathrm{Ct}$ values. Relative sensitivity of the rRT-PCR was determined to be 8 TCID $_{50}$ utilizing serial dilutions infected cell supernatant and comparing level of detection by rRT-PCR and virus isolation utilizing BHK-21 cells as described above (see Appendix A).

\section{RESULTS}

\subsection{Clinical outcome and virus distribution}

Animals inoculated in the coronary bands exhibited transient fever $\left(\geq 40{ }^{\circ} \mathrm{C}\right)$ and blanching on the entire extension of the coronary bands by $24 \mathrm{hpi}$ followed by vesicles in the epithelium of the coronary band by 48 hpi. All coronary bandinoculated animals developed vesicular le- sions in the inoculated feet by $48 \mathrm{hpi}$ resulting in clinical scores of 8 according to the scale described in the materials and methods above. Animal \#102 inoculated only on the right feet developed lesions only at inoculation sites and had the maximum score of 4 . The animal inoculated in the tongue showed blanching and fluidfilled vesicles in the tongue by $24 \mathrm{~h}$ that were ruptured by $48 \mathrm{~h}$ with epithelium loss on the tongue, leaving a large eroded surface. No lesions were observed at other sites. Fever and/or lesions were absent in the animals inoculated in the skin of the flank or neck; no clinical signs were observed in mock-inoculated animals.

Virus was not detected in whole blood, or plasma obtained at $0,12,24,48$ and 72 hpi from nine inoculated animals regardless of the route of inoculation or time after infection. OPF was negative as most coronary band or flank skininoculated animals, except in animals 30 and 31 , where virus was detected in OPF at 72 hpi. Tongue-inoculated animal 699 had vesicular lesions on the tongue; therefore OPF samples were not obtained since they would become contaminated by virus in the mouth.

Cattle were euthanized and various tissues were collected and analyzed both by virus isolation and real-time RT-PCR. In 4 of 6 coronary band-inoculated animals, virus was only found at the inoculation site and at the primary draining lymph nodes; i.e. prescapular or popliteal draining the front or the rear feet respectively. Coronary band-inoculated animals 30 and 31 , in addition to the inoculation site, had virus in OPF but no lesions in the mouth or tongue, yet at necropsy, virus was found in tonsil and lymph nodes draining the mouth (retropharyngeal, and parotid) (Tab. I). In the case of animal 699, inoculated in the tongue, VSNJV virus was found in the tongue epithelium, retropharyngeal, parotid and submandibular lymph nodes and in the tonsil, but not in coronary 
Table I. Distribution of VSNJV in inoculated cattle determined by virus isolation and real-time RT-PCR.

\begin{tabular}{|c|c|c|c|c|c|c|c|c|}
\hline & & & & Inoct & ation & & & \\
\hline & & Four c & ronary & bands & & Right & Flank/ & Tongue \\
\hline & & & & & & bands & skin & \\
\hline Animal ID** & 10 & 30 & 31 & 725 & 754 & 102 & $12 / 148 * *$ & 699 \\
\hline Tissue $^{\mathrm{a}}$ & & Virus I & blatior & positiv & samp & s (left/right & when applica & \\
\hline Coronary band & $2 / 2$ & $2 / 2$ & $2 / 2$ & $2 / 2$ & $2 / 2$ & $0 / 2$ & $0 / 0$ & $0 / 0$ \\
\hline Prescapular $\ln *$ & $1 / 0$ & $1 / 1$ & $1 / 0$ & $1 / 1$ & $1 / 1$ & $0 / 1$ & $0 / 0$ & $0 / 0$ \\
\hline Popliteal ln* & $1 / 1$ & $1 / 0$ & $1 / 1$ & $1 / 1$ & $1 / 1$ & $0 / 1$ & $0 / 0$ & $0 / 0$ \\
\hline Axillary $\ln \#$ & $0 / 0^{\mathrm{b}}$ & $0 / 0$ & $1 / 0$ & $0 / 0$ & $0 / 0$ & $0 / 1^{\mathrm{d}}$ & $0 / 0$ & $0 / 0$ \\
\hline Prefemoral $\ln \#$ & $0 / 0$ & $0 / 0$ & $0 / 0$ & $0 / 0$ & $0 / 0$ & $0 / 0$ & $0 / 0$ & $0 / 0$ \\
\hline Tongue & 0 & 0 & 0 & 0 & 0 & 0 & 0 & 1 \\
\hline Snout skin & 0 & 0 & 0 & 0 & 0 & 0 & n.d. ${ }^{\mathrm{c}}$ & 0 \\
\hline Nasal epithelium & $0 / 0$ & $0 / 0$ & $0 / 0$ & $0 / 0$ & $0 / 0$ & $0 / 0$ & n.d. & $0 / 0$ \\
\hline Tonsil & $0 / 0$ & $1 / 0$ & $0 / 1$ & $0 / 0$ & $0 / 0$ & $0 / 0$ & $0 / 0$ & $1 / 1$ \\
\hline Retropharyngeal ln & $0 / 0$ & $1 / 0$ & $0 / 0$ & $0 / 0$ & $0 / 0$ & $0 / 0$ & $0 / 0$ & $1 / 1$ \\
\hline Parotid ln & $0 / 0$ & $1 / 0$ & $0 / 0$ & $0 / 0$ & $0 / 0$ & $0 / 0$ & $0 / 0$ & $1 / 1$ \\
\hline Submandibular ln & $0 / 0$ & $0 / 0$ & $0 / 0$ & $0 / 0$ & $0 / 0$ & $0 / 0$ & $0 / 0$ & $1 / 1$ \\
\hline Mandibular salivary gland & $0 / 0$ & $0 / 0$ & $0 / 0$ & $0 / 0$ & $0 / 0$ & $0 / 0$ & n.d. & $0 / 0$ \\
\hline Brain (Olfactory Bulb) & $0 / 0$ & $0 / 0$ & $0 / 0$ & $0 / 0$ & $0 / 0$ & $0 / 0$ & n.d. & $0 / 0$ \\
\hline Mediastinal ln & 0 & 0 & 0 & n.d. & n.d. & 0 & n.d. & 0 \\
\hline Mesenteric ln & 0 & 0 & 0 & 0 & 0 & 0 & n.d. & 0 \\
\hline Iliac ln & 0 & 0 & 0 & n.d. & n.d. & 0 & n.d. & 0 \\
\hline Heart & 0 & 0 & 0 & n.d. & n.d. & 0 & n.d. & n.d. \\
\hline Lung & $0 / 0$ & $0 / 0$ & $0 / 0$ & $0 / 0$ & $0 / 0$ & $0 / 0$ & n.d. & $0 / 0$ \\
\hline Kidney & $0 / 0$ & $0 / 0$ & $0 / 0$ & $0 / 0$ & $0 / 0$ & $0 / 0$ & n.d. & $0 / 0$ \\
\hline Liver & 0 & 0 & 0 & 0 & 0 & 0 & n.d. & 0 \\
\hline Spleen & 0 & 0 & 0 & 0 & 0 & 0 & 0 & 0 \\
\hline Payer patches & 0 & 0 & 0 & n.d. & n.d. & 0 & n.d. & 0 \\
\hline Small intestine/duodenum & 0 & 0 & 0 & n.d. & n.d. & 0 & n.d. & 0 \\
\hline Large intestine/colon & 0 & 0 & 0 & n.d. & n.d. & 0 & n.d. & 0 \\
\hline Flank/neck skin & n.d. & n.d. & n.d. & n.d. & n.d. & n.d. & $0 / 1$ & n.d. \\
\hline
\end{tabular}

${ }^{a}$ All animals euthanized at 72 hpi except \#12 euthanized at 48 hpi.

${ }^{\mathrm{b}}$ Negative in virus isolation.

${ }^{c}$ n.d., not done.

${ }^{\mathrm{d}}$ Positive by RT-PCR only.

* Primary draining lymph node (ln).

\# Secondary draining $\ln$.

** Neck skin inoculated animal (\#148) had the same results as animal 12 except that residual virus was found on the inoculation site skin at necropsy $(48 \mathrm{~h})$. 


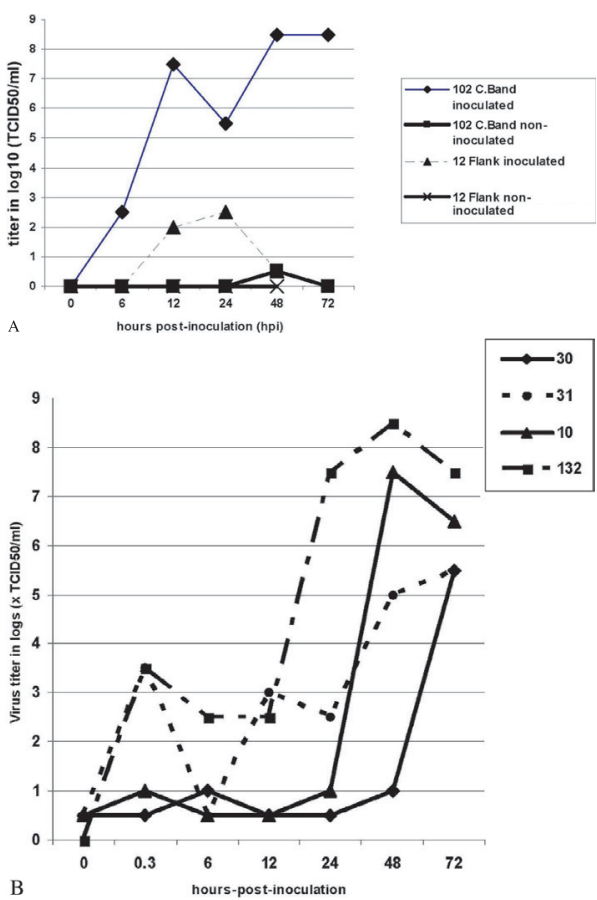

Figure 1. A. Growth curve of VSNJV in skin from animals inoculated on the right coronary bands (\#102) or on skin of the flank (\#12). B. Growth curve of four additional animals inoculated in the coronary bands.

bands or in lymph nodes draining the feet (Tab. I).

To explore the effect of the inoculation site on lesion development and virus distribution we inoculated three cattle; one animal was inoculated on the right coronary bands, leaving the left coronary bands as mock-inoculated controls (animal 102), and two other animals were inoculated intradermally on the skin of the flank or neck, sites with VSV lesions are not reported (animals 12 and 148). Typical vesicular lesions and an increase in viral titer of $8 \log _{10} \mathrm{TCID}_{50}$ by $48 \mathrm{hpi}$ were observed only on the right coronary bands of animal 102 (Fig. 1A). Similar results were observed in four other coronary bandinoculated animals, as shown in Figure 1B.
In contrast, intradermal inoculation of the flank or neck skin in animals 12 and 148 (not shown) respectively, resulted in no lesions and a virus titer of less than $3 \log _{10}$ TCID $_{50}$ was detected in skin biopsies (Fig. 1A). Virus was recovered from the right coronary bands and draining lymph nodes in animal 102, but not from the leftside samples nor from any other organ or lymph nodes from this animal or animals 12 and 148 (Tab. I).

\subsection{VSV distribution in infected tissues}

Distribution of VSV in infected tissues was determined by immunohistochemistry utilizing VSNJV-specific antibodies. In the coronary band, virus antigens were primarily associated with the upper layers of the skin; particularly the "stratum spinosum" and "stratum granulosum". Early after infection (6-12 h), only cells in the upper layers stained for viral antigens; these cells were mostly associated with micro vesicles that coalesced into larger vesicles by 72 hpi (Fig. 2A). As vesicles became larger and filled with fluid (48 to $72 \mathrm{hpi}$ ), a mixed population of inflammatory cells infiltrated the lesion site and some distinct VSV-antigen containing cells with dendritic cell-like morphology were observed in the lower layers of the dermis (Fig. 2A inset). In the skin of the flank sporadic antigen positive cells were observed, mostly associated with hair follicles and connective tissues in the dermis (Fig. 2B).

In the draining lymph nodes, few antigen-positive cells were observed by 72 hpi, mostly in the paracortex area and to a lesser extent in the trabeculae, mantle and germinal centers (Fig. 3). In an earlier experiment, virus was detected by virus isolation and real-time RT-PCR as early as 24 hpi in draining lymph nodes but antigen-positive cells were not observed until 48-72 hpi (data not shown). 


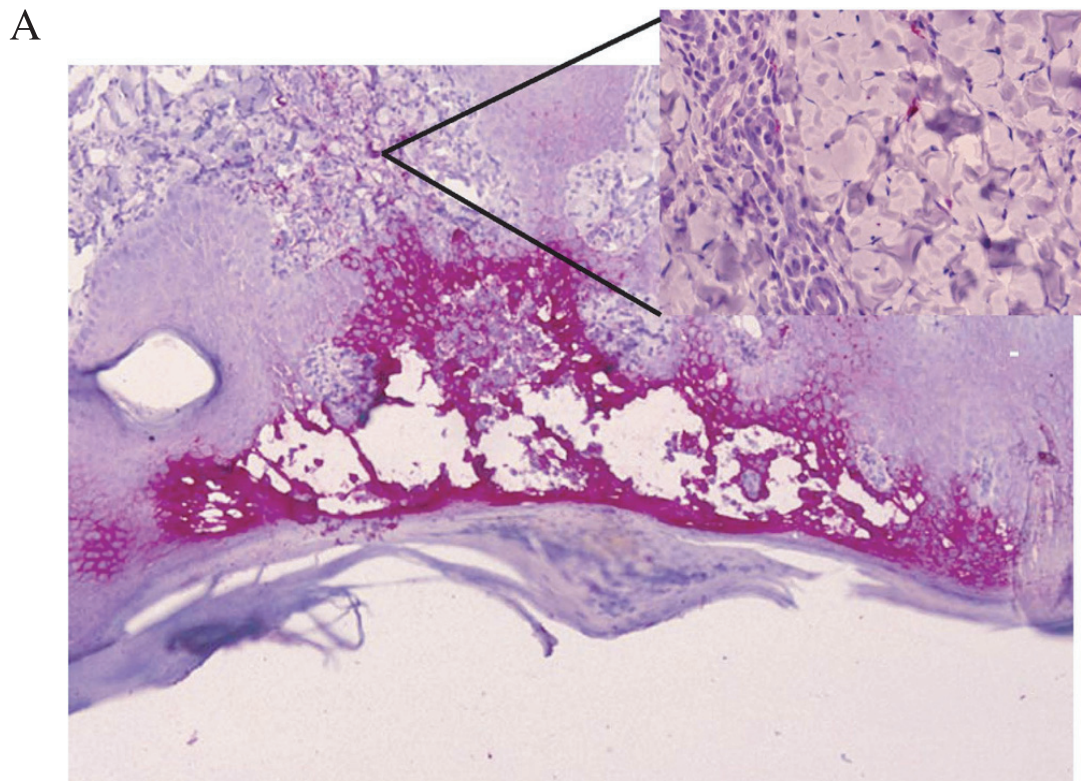

B
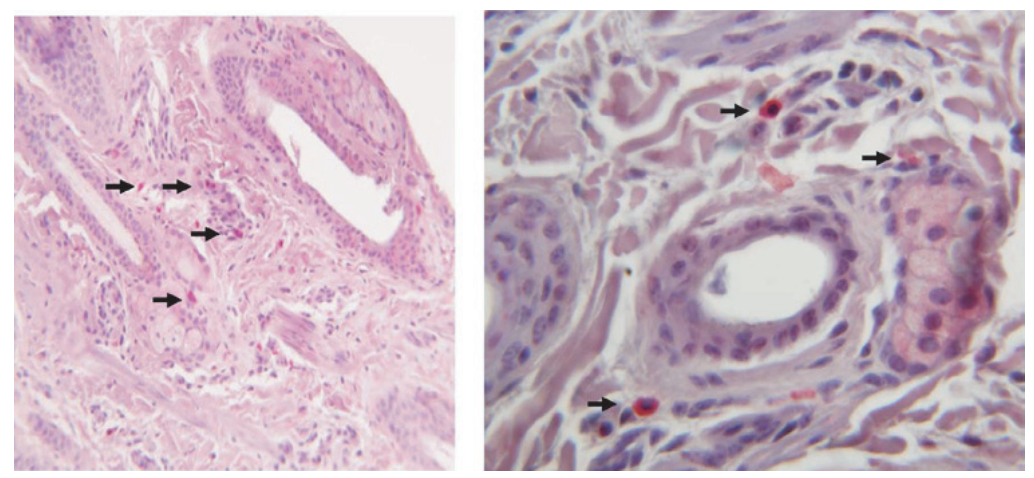

Figure 2. Skin sections of animals inoculated in the coronary band (A) or flank skin (B) stained with anti-VSNJV antibodies and counterstained with Gill Haematoxilin. VSNJV antigen-positive cells are shown in pink. Panel A shows a vesicular lesion at low $(\times 100)$ and high magnification $(\times 400)$ detail of the dermis area (inset). Panel B shows low $(\times 100)$ and high $(\times 400)$ magnification of inoculated flank skin. Arrows mark VSNJV antigen-positive cells.

\subsection{Characterization of infected cells by immunofluorescence confocal microscopy}

In order to characterize VSNJV antigenpositive cells in coronary band and flank skin, we utilized confocal microscopy and double staining with specific antibodies against VSNJV and antibodies to three cellular markers: cytokeratin (a marker for keratinocytes), MHC-II clone TH14B (a marker for dendritic cells, B-cells, macrophages and monocytes) and MAC387 (a marker for granulocytes, monocytes and tissue macrophages). The majority of cells staining with VSNJV-specific antibodies in coronary bands were also positive for cytokeratin staining suggesting that 

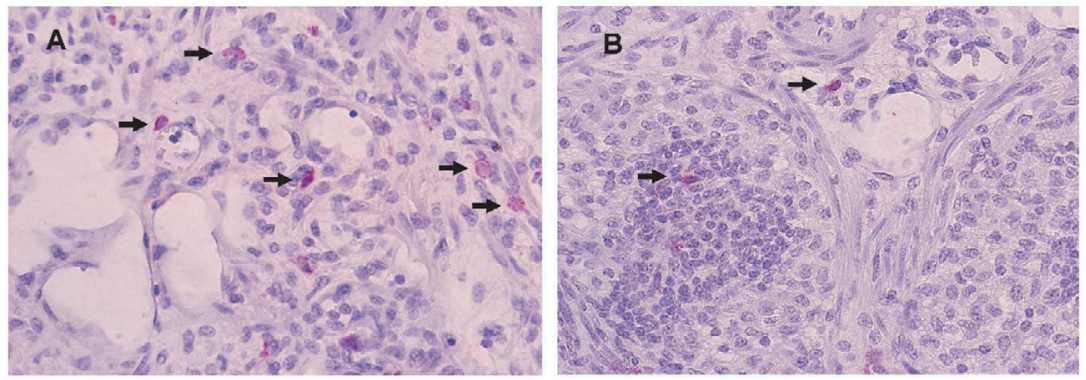

Figure 3. Sections of prescapular lymph nodes from an animal inoculated with VSNJV $48 \mathrm{~h}$ earlier, stained with guinea pig antibodies to VSNJV and counterstained with Gill Haematoxilin. VSNJV antigen-positive cells are shown in the paracortex area (A) and in the trabeculae and germinal centers (B).

keratinocytes are primary targets for viral replication early during infection and support virus growth (Fig. 4). VSNJV antigen-positive cells of the middle and upper stratum spinosum and in the stratum granulosum of the coronary band showed strong staining with anti-cytokeratin antibodies particularly in those areas with micro vesicles. In flank skin, VSV staining was only observed at 24 hpi co-localizing with cytokeratin-positive staining in cells associated with hair follicles (Fig. 4). By 48 hpi VSV positive cells were no longer observed in the flank (not shown).

To further characterize VSV infected cells, we stained coronary band and To: Command not found.

flank skin tissue sections with antibodies to human MHC-II antigens. Despite the fact that a number of MHC-II-positive cells were found in and around the coronary band lesions, particularly at 48-72 hpi, only a few of these cells stained for VSV antigens and most of them were located in the deep dermis (Fig. 5). In flank skin sections MHCII-positive cells were observed but no co-localization with VSV antigens was observed (Fig. 5). These results were confirmed utilizing an antibody specific for bovine MHC-II antigens (not shown).

Cells stained by monoclonal antibody MAC-387 were frequently observed in the coronary band particularly after $48-72 \mathrm{hpi}$, indicating inflammatory cell infiltration. However, these cells did not stain for VSNJV antigen (Fig. 6). Few MAC-387positive cells were observed in the flank skin at any time post inoculation and none were stained for VSNJV-antigen (Fig. 6).

\section{DISCUSSION}

Little is known about the mechanisms of VSV transmission, tissue tropism, virus distribution and factors determining the localization of vesicular lesions in its most commonly affected natural host; the bovine. Pathogenesis studies in laboratory mice are not relevant to clinical disease in cattle since mice present neurological clinical signs and not vesicular lesions like those observed in livestock species. Early studies in cattle utilized tongue inoculation, an unlikely route of infection resulting from insect bite $[5,17,22]$. The inoculation model described here is more similar to natural skin infection and is the first in cattle that consistently results in vesicular lesions and at the same time allows sequential sampling of the skin and tracking of viral growth using skin punch biopsies. 


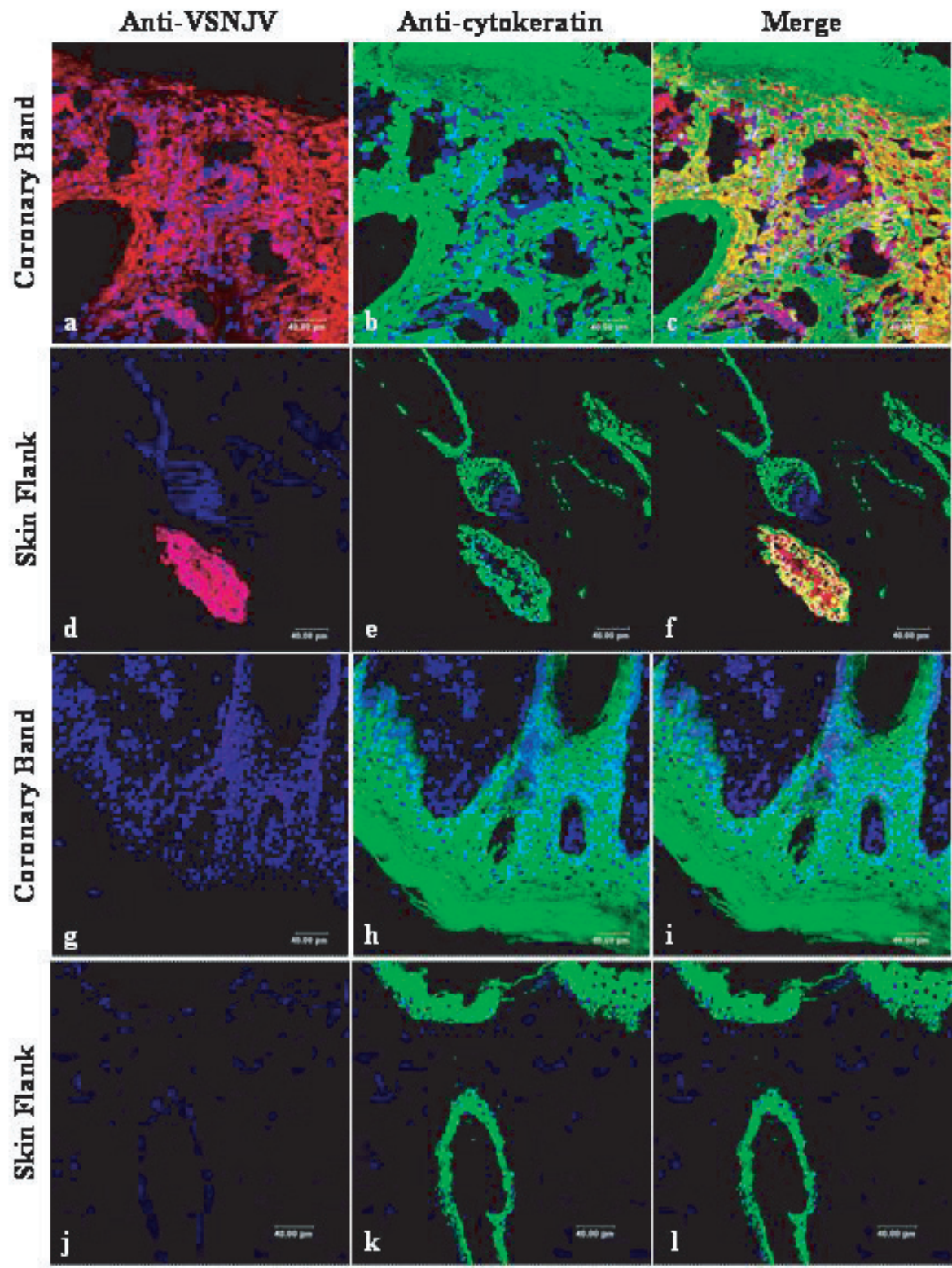

Figure 4. Localization of VSNJV antigen in frozen sections of tissues from infected steers. Cryosectioned tissues from the coronary band ( $48 \mathrm{hpi}, \mathrm{a}-\mathrm{c}$ inoculated, $\mathrm{g}-\mathrm{i}$ non-inoculated) and skin flank (24 hpi, d-f inoculated, $\mathrm{j}-1$ non-inoculated) were processed for immunofluorescence staining and confocal microscopy with anti-VSNJV and anti-cytokeratin antibodies. VSNJV was visualized with Alexa Fluor 594 (red), cytokeratin was visualized with Alexa Fluor 488 (green). Cells were counterstained with TOPRO-iodide 642/661 (blue) to reveal the nuclei. 


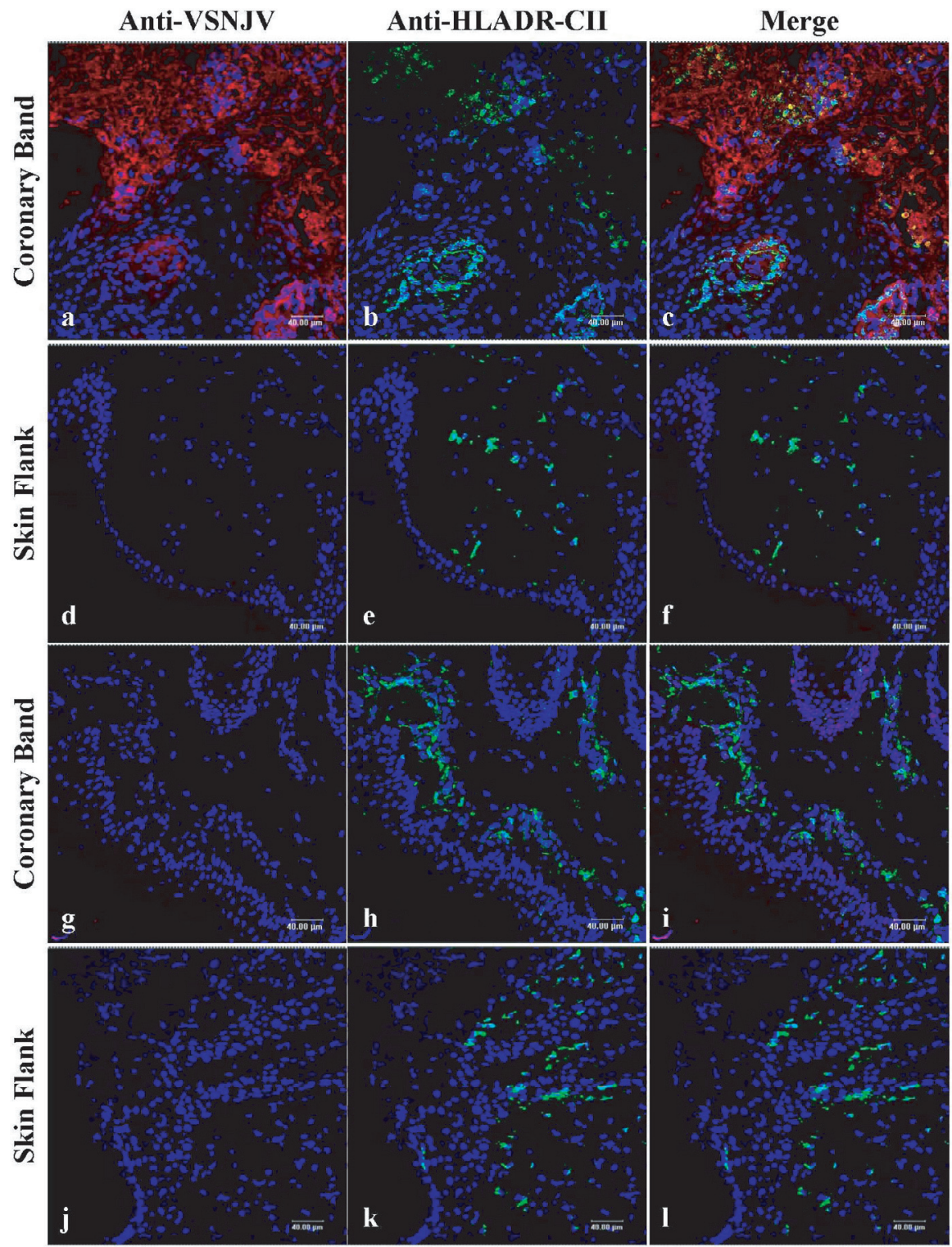

Figure 5. Localization of VSNJV antigen in frozen sections of tissues from two infected cattle at 48 hpi. Cryosectioned tissues from inoculated coronary band ( $\mathrm{a}-\mathrm{c}$ inoculated, $\mathrm{g}-\mathrm{i}$ non-inoculated) and inoculated skin of the neck ( $\mathrm{d}-\mathrm{f}$ inoculated, $\mathrm{j}-1$ non-inoculated) were processed for immunofluorescence staining and confocal microscopy with anti-VSV and anti-HLADR Class II antibodies. VSV was visualized with Alexa Fluor 594 (red), HLADR class II was visualized with Alexa Fluor 488 (green). Cells were counterstained with TOPRO-iodide 642/661 (blue) to reveal the nuclei. 

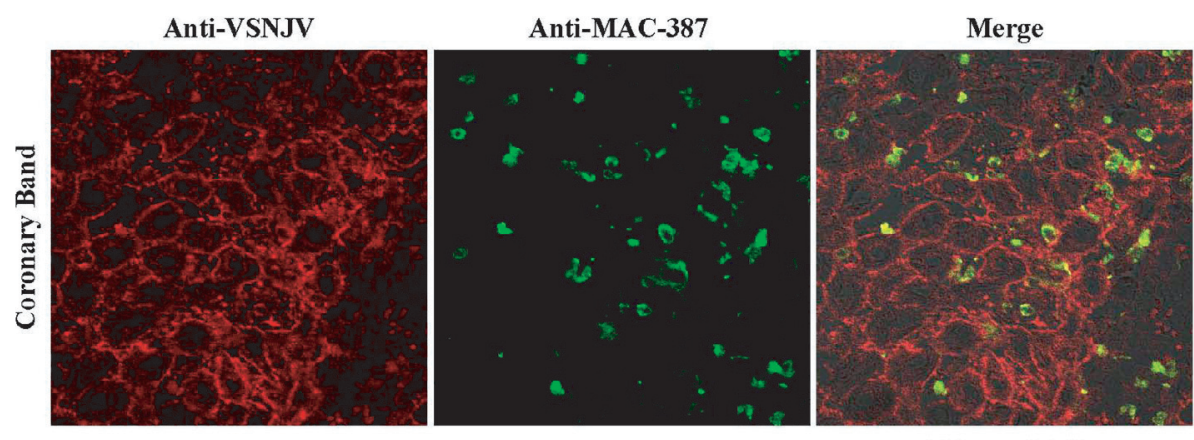

Merge - DIC
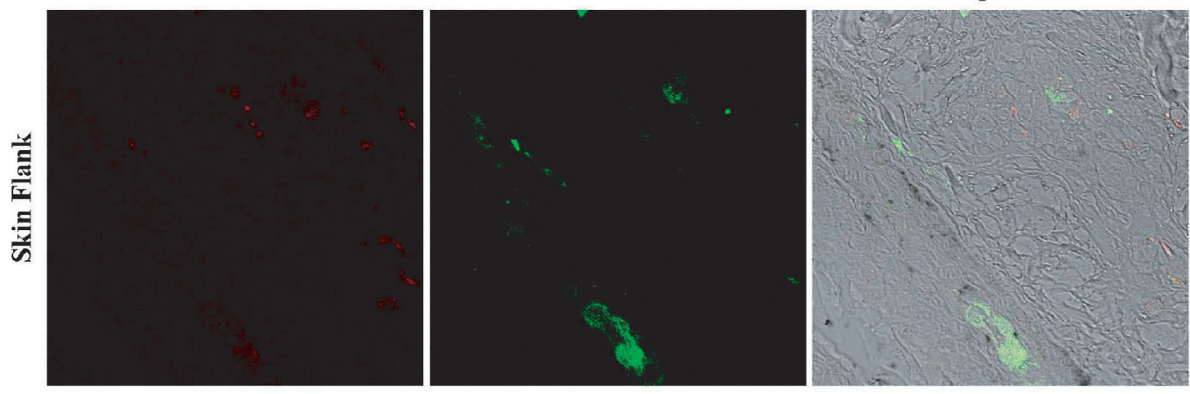

Figure 6. Localization of VSNJV antigen in frozen sections of tissues from two cattle, one inoculated on the coronary band and one on the skin of the flank 48 earlier. Cryosectioned tissues from the inoculated coronary band (upper panel) and inoculated skin of the flank (lower panel) were processed for immunofluorescence staining and confocal microscopy with anti-VSNJV and MAC-387 antibodies. VSV was visualized with Alexa Fluor 594 (red), HLADR class II was visualized with Alexa Fluor 488 (green).

Virus distribution in infected animals has been a long standing question that has implications not only for the pathogenesis and transmission of this virus but also for regulatory issues related to the approval of VSV as a potential vaccine and anti-tumor vector and for resumption of trade and animal movement after quarantines imposed during VSV outbreaks. Postmortem examination demonstrated that VSNJV caused localized infections with virus recovered only from the inoculation site and regional draining lymph nodes, but not from blood or internal organs. Furthermore, no virus was detected on the left feet of animals inoculated on the right side coronary bands and only residual virus was detected one time on a left foot, likely the result of sur- face contamination from virus shedding of the right feet. Only in two out of seven coronary band-inoculated cattle, was virus found in the pharyngeal fluid, tonsils or lymph nodes draining the oropharynx. This is an interesting finding since tonsils seem to be an important site for viral replication in swine but had not previously been reported in cattle $[2,11,14,23]$. We could not determine the source of virus in these two cattle, but it is possible that their mouth came in close contact with their inoculated feet during the experiment.

Virus was not detected in whole blood or in plasma at any time post inoculation. This result confirms previous reports in swine, horses and cattle [10, 11, 14]. It could be argued that the samples tested had 
low titers or that infectious virus was not detectable due to virus inhibitory factors such as interferon, in the blood. However, this is unlikely the case since we failed to detect viral RNA using a real-time RTPCR capable of detecting 8 TCID $_{50}$ of VSNJV in "spiked" normal blood and plasma samples (Appendix A). Therefore, we hypothesize that the mechanism by which virus traveled from the inoculation site to the regional lymph nodes was cell associated via the lymphatic system. It is also possible that the virus was cell-associated in the blood in amounts undetectable by real-time RT-PCR. The lack of a viremic phase in cattle for an arthropod-borne virus like VSV is puzzling. However, it is possible that livestock are dead-end hosts and that other mammalian hosts might be responsible for maintaining the natural virus-insect cycle $[3,4]$. Alternatively, recent studies have shown horizontal insectto-insect transmission of VSV while cofeeding in non-viremic mammalian hosts theoretically making viremia unnecessary for insect to insect transmission [13].

The localized nature of VSNJV infection in cattle was also confirmed after tongue inoculation, where in postmortem examination virus was only found in the tongue and head associated tissues, but not in coronary bands or other organs. These results were consistent with field clinical observations in cattle where lesions rarely occur at more than one site, but contrast those in swine, where lesions in the mouth and feet are commonly observed both in field infections and laboratory infected animals [12,23]. The basis of this difference is not clear but swine are known to shed virus in saliva (from tonsil infection) for extended periods and numerous skin abrasions occur during fighting when housed in groups together [24].

In natural VSV infections, vesicular lesions appear at specific sites including the feet, mouth, or teats in lactating animals [28]. Previous studies in swine, showed that only intradermal inoculation of the snout or coronary band resulted in lesion formation [11]. Similar results were obtained by inoculation with black flies, with skin lesions observed only when flies were allowed to feed on the skin of the snout but not when they fed on the skin of the abdomen in swine [14]. We demonstrate that in cattle, the site of skin inoculation not only determines the clinical outcome but also the ability of VSNJV to induce local replication. Inoculation of the flank skin resulted in no lesions and little viral replication at the inoculation site. The mechanism of this restriction remains unclear, but we showed a marked contrast in distribution of virus antigen-positive cells between the coronary band, where extensive replication occurs and flank skin where replication is limited and infection does not progress to clinical lesions. In coronary bands there was a clear association of viral antigen with keratinocytes located in the upper layers of the epidermis where vesicular lesions later developed, whereas in flank skin, only few antigenpositive keratinocytes were transiently observed in association with hair follicles. There are important histological and structural differences between the skin of the coronary band and the flank skin that may explain this difference in supporting viral growth. The coronary band skin has multiple layers of keratinocytes forming thick epidermal layers (stratum basale and stratum spinosum), while the flank skin has thin epidermal layers with a smaller number of keratinocytes that may not be sufficient to support viral replication and vesicle formation.

This study is the first detailed description of VSV pathogenesis in cattle, the most frequently affected species during VSV outbreaks. The inoculation model will be useful in future pathogenesis studies, such as determining the cellular and molecular events after VSV infection by 
insect bite, or the effect of individual viral genes on VSV virulence in a natural host.

Utilizing the model presented here we have shown that after penetration through scarification of the coronary band skin VSNJV infects and replicates primarily in keratinocytes of the stratum granulosum and stratum spinosum resulting in micro vesicles that coalesce to form larger vesicles at the coronary band. Virus antigen was not observed in significant quantities associated with MHC-II or MAC-387 cellular markers indicating that keratinocytes are the primary and most important cell type supporting VSNJV infection.

\section{ACKNOWLEDGEMENTS}

This work was supported by the United States Department of Agriculture (CRIS 194032000-040-00D). We thank Dr Jose Del C. Barrera for carrying out virus isolation and George Smoliga for real-time PCR tests. Dr Barbara Drolet helped on the animal experiments and provided antibody to VSNJV, Dr Corrie Brown for valuable advice and Amy Kozer for histological technical assistance and Melanie Prarat for reading the manuscript and providing valuable suggestions.

\section{REFERENCES}

[1] Balachandran S., Barber G.N., Vesicular stomatitis virus (VSV) therapy of tumors, IUBMB Life (2000) 50:135-138.

[2] Clarke G.R., Stallknecht D.E., Howerth E.W., Experimental infection of swine with a sandfly (Lutzomyia shannoni) isolate of vesicular stomatitis virus, New Jersey serotype, J. Vet. Diagn. Invest. (1996) 8:105-108.

[3] Comer J.A., Stallknecht D.E., Nettles V.F., Incompetence of domestic pigs as amplifying hosts of vesicular stomatitis virus for Lutzomyia shannoni (Diptera: Psychodidae), J. Med. Entomol. (1995) 32:741-744.

[4] Comer J.A., Stallknecht D.E., Nettles V.F., Incompetence of white-tailed deer as amplifying hosts of vesicular stomatitis virus for
Lutzomyia shannoni (Diptera: Psychodidae), J. Med. Entomol. (1995) 32:738-740.

[5] Cotton W.E., Vesicular stomatitis and its relation to the diagnosis of foot-and-mouth disease, J. Am. Vet. Med. Assoc. (1926) 69:313-332.

[6] Cupp E.W., Mare C.J., Cupp M.S., Ramberg F.B., Biological transmission of vesicular stomatitis virus (New Jersey) by Simulium vittatum (Diptera: Simuliidae), J. Med. Entomol. (1992) 29:137-140.

[7] Falke D., Rowe W.P., Mouse disease due to vesicular stomatitis virus. II. Pathology of organ lesions and the involvement of the central and peripheral nervous systems, Arch. Gesamte Virusforsch. (1965) 17:560-576 (in German).

[8] Flanagan E.B., Zamparo J.M., Ball L.A., Rodriguez L.L., Wertz G.W., Rearrangement of the genes of vesicular stomatitis virus eliminates clinical disease in the natural host: new strategy for vaccine development, J. Virol. (2001) 75:6107-6114.

[9] Fultz P.N., Holland J.J., Differing responses of hamsters to infection by vesicular stomatitis virus Indiana and New Jersey serotypes, Virus Res. (1985) 3:129-140.

[10] House J.A., House C., Dubourget P., Lombard M., Protective immunity in cattle vaccinated with a commercial scale, inactivated, bivalent vesicular stomatitis vaccine, Vaccine (2003) 21:1932-1937.

[11] Howerth E.W., Stallknecht D.E., Dorminy M., Pisell T., Clarke G.R., Experimental vesicular stomatitis in swine: effects of route of inoculation and steroid treatment, J. Vet. Diagn. Invest. (1997) 9:136-142.

[12] Martinez I., Rodriguez L.L., Jimenez C., Pauszek S.J., Wertz G.W., Vesicular stomatitis virus glycoprotein is a determinant of pathogenesis in swine, a natural host, J. Virol. (2003) 77:8039-8047.

[13] Mead D.G., Ramberg F.B., Besselsen D.G., Mare C.J., Transmission of vesicular stomatitis virus from infected to noninfected black flies co-feeding on nonviremic deer mice, Science (2000) 287:485-487.

[14] Mead D.G., Gray E.W., Noblet R., Murphy M.D., Howerth E.W., Stallknecht D.E., Biological transmission of vesicular stomatitis virus (New Jersey serotype) by Simulium vittatum (Diptera: Simuliidae) to domestic swine (Sus scrofa), J. Med. Entomol. (2004) 41:78-82. 
[15] Patterson W.C., Jenney E.W., Holbrook A.A., Experimental Infections with vesicular stomatitis in swine I. Transmission by direct contact and feeding infected meat scraps, United States Livestock Sanitary Association Proceedings, 1955, 368 p.

[16] Remmers L., Perez E., Jimenez A., Vargas F., Frankena K., Romero J.J., Salman M., Herrero M.V., Longitudinal studies in the epidemiology of vesicular stomatitis on Costa Rican dairy farms, Ann. NY Acad. Sci. (2000) 916:417-430.

[17] Ribelin W., The cytopathogenesis of vesicular stomatitis virus infection in cattle, Am. J. Vet. Res. (1958) 19:66-73.

[18] Roberts A., Buonocore L., Price R., Forman J., Rose J.K., Attenuated vesicular stomatitis viruses as vaccine vectors, J. Virol. (1999) 73:3723-3732.

[19] Rodriguez L.L., Vernon S., Morales A.I., Letchworth G.J., Serological monitoring of vesicular stomatitis New Jersey virus in enzootic regions of Costa Rica, Am. J. Trop. Med. Hyg. (1990) 42:272-281.

[20] Rodriguez L.L., Nichol S.T., Webster R.G., Granoff A., in: Vesicular Stomatitis Viruses, Encyclopedia of Virology, 2nd edition, Academic Press, London, 1999, pp. 1910-1919.

[21] Rodriguez L.L., Bunch T.A., Fraire M., Llewellyn Z.N., Re-emergence of vesicular stomatitis in the western United States is associated with distinct viral genetic lineages, (2000) 271:171-181.

[22] Seibold H., Sharp J., A revised concept of the pathological changes of the tongue in cattle with vesicular stomatitis, Am. J. Vet. Res. (1960) 21:35-51.
[23] Stallknecht D.E., Howerth E.W., Reeves C.L., Seal B.S., Potential for contact and mechanical vector transmission of vesicular stomatitis virus New Jersey in pigs, Am. J. Vet. Res. (1999) 60:43-48.

[24] Stallknecht D.E., Perzak D.E., Bauer L.D., Murphy M.D., Howerth E.W., Contact transmission of vesicular stomatitis virus New Jersey in pigs, Am. J. Vet. Res. (2001) 62:516-520.

[25] Sur J.H., Doster A.R., Christian J.S., Galeota J.A., Wills R.W., Zimmerman J.J., Osorio F.A., Porcine reproductive and respiratory syndrome virus replicates in testicular germ cells, alters spermatogenesis, and induces germ cell death by apoptosis, J. Virol. (1997) 71:9170-9179.

[26] Tanimoto T., Ohtsuki Y., Evaluation of antibodies reactive with porcine lymphocytes and lymphoma cells in formalinfixed, paraffin-embedded, antigen-retrieved tissue sections, Am. J. Vet. Res. (1996) 57:853-859.

[27] Tesh R.B., Chaniotis B.N., Johnson K.M., Vesicular stomatitis virus, Indiana serotype: multiplication in and transmission by experimentally infected phlebotomine sandflies (Lutzomyia trapidoi), Am. J. Epidemiol. (1971) 93:491-495.

[28] Vanleeuwen J.A., Rodriguez L.L., WaltnerToews D., Cow, farm, and ecologic risk factors of clinical vesicular stomatitis on Costa Rican dairy farms, Am. J. Trop. Med. Hyg. (1995) 53:342-350. 
Appendix A. Sensitivity of real-time RT-PCR (rRT-PCR). Supernatant from BHK-21 cells infected with VSNJ-95COB was titrated in serial dilutions by virus isolation in BHK-21 cells or by rRTPCR. The results represent averages of two independent assays.

\section{Sensitivity of rRT-PCR for VSNJV (95COB)}

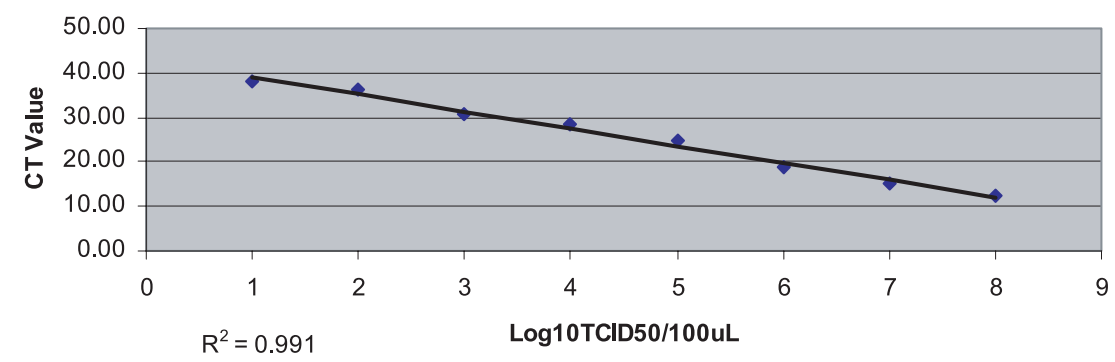

${ }^{\star}$ Cutoff value $<37$

Level of detection: $9 \mathrm{TCID}_{50}$

\begin{tabular}{|rcc|}
\hline \multicolumn{2}{|l|}{ Titer $\mathrm{TCID}_{50} / 2.5 \mu \mathrm{L}$} & Avg. CT $(\mathrm{n}=2)$ \\
\hline No template & & 38.79 \\
& 0.8 & 38.17 \\
8.8 & $36.09\left(^{*}\right)$ \\
88 & 30.75 \\
880 & 28.22 \\
8800 & 24.87 \\
88000 & 18.58 \\
880000 & 15.36 \\
8800000 & 12.19 \\
\hline
\end{tabular}

